\title{
Cengestato
}

\section{Bibliotecas públicas e letramento informacional}

\author{
Mirian Ferreira Alves \\ Mestre; Universidade de Brasília; mirialves@gmail.com \\ Emir José Suaiden \\ Pós-doutor; Universidade de Brasília; \\ emir@unb.br
}

\begin{abstract}
Resumo: A Sociedade da Informação apresenta novos desafios e oportunidades para as bibliotecas públicas, que são apontadas por diversos autores como instituições essenciais para a formação de cidadãos plenos, aptos à sobrevivência na Sociedade da Informação. Neste sentido, destaca-se o letramento informacional, essencial para a formação de aprendizes autônomos, capazes de acessar a informação e utilizá-la de modo crítico e ético. Este artigo discute o papel e a atuação das bibliotecas públicas na promoção do letramento informacional, para tal utilizando-se do método da pesquisa bibliográfica, que envolveu a identificação e análise das principais pesquisas e discussões presentes na literatura internacional. Este artigo apresenta ainda abordagens alternativas de letramento informacional como uma alternativa para sua compreensão e desenvolvimento no âmbito das bibliotecas públicas. O resultado da análise permitiu identificar as principais questões que permeiam o tema investigado.
\end{abstract}

Palavras-chave: Letramento informacional. Bibliotecas públicas

\section{Introdução}

O Manifesto da International Federation of Library Associations and Institutions/United Nations Educational, Scientific and Cultural Organization (IFLA/UNESCO) sobre bibliotecas públicas define a biblioteca pública como uma porta de acesso local ao conhecimento, capaz de proporcionar as condições básicas para a educação permanente, a tomada de decisões independentes e o desenvolvimento cultural do indivíduo e dos grupos sociais (KOONTZ; GUBBIN, 2012). A biblioteca pública traz no seu bojo de finalidades e objetivos grandes desafios relacionados à educação, ao acesso à informação, à participação social e à cidadania, e estes desafios se renovam constantemente e 
se moldam às novas necessidades da sociedade e ao contexto histórico e social vigente.

No contexto atual, onde o conhecimento e a informação constituem as forças fundamentais nos âmbitos econômico e social, a biblioteca pública se destaca por seu potencial democrático e inclusivo, e sua capacidade de contribuição para a formação cidadã, mas também enfrenta novos desafios no sentido de adaptar-se à nova realidade, às novas necessidades sociais e ao avanço tecnológico.

Esta nova ordem social, a Sociedade da Informação, é comumente entendida como uma nova forma de organização social, política e econômica baseada na informação. Neste cenário, novas habilidades e competências são exigidas dos indivíduos - como lidar com as novas tecnologias, reconhecer suas necessidades de informação, saber onde e como buscá-la, fazer uso crítico e ético da informação a que se tem acesso, aprender a aprender e manter-se em constante aprendizagem ao longo da vida. Deste modo, pode-se afirmar que o letramento informacional e a aprendizagem ao longo da vida estão estritamente relacionados com o papel da biblioteca pública e com sua atuação na Sociedade da Informação.

Tendo em vista que se trata de um processo contínuo que não se esgota, o letramento informacional permeia o aprendizado ao longo de toda a vida. Conforme a Declaração de Alexandria sobre competência informacional e aprendizado ao longo da vida (INTERNATIONAL FEDERATION OF LIBRARY..., 2005), o letramento informacional está no cerne do aprendizado ao longo da vida, pois "[...]capacita as pessoas em todos os caminhos da vida para buscar, avaliar, usar e criar a informação de forma efetiva para atingir suas metas pessoais, sociais, ocupacionais e educacionais[...]", sendo considerado um direito humano básico em um mundo digital, com potencial para promover a inclusão social em todas as nações.

No Brasil, o letramento informacional tem sido mais relacionado ao contexto educacional, recebendo mais destaque no âmbito das bibliotecas escolares e universitárias, enquanto ao redor do mundo vêm sendo desenvolvidos trabalhos e discussões sobre o letramento informacional também 
no contexto das bibliotecas públicas, ainda que em menor grau. Por vocação as bibliotecas públicas são consideradas importantes espaços para o aprendizado ao longo da vida, dada a sua função educativa, sua penetrabilidade e presença constante na vida da comunidade. É o que ressalta Kahlert $\left(2000^{1}\right.$ apud HARDING, 2008), ao afirmar que a biblioteca pública possui uma gama diversificada de usuários e potencial para alcançar todos os segmentos da comunidade, desde crianças até idosos, além de grupos minoritários e de distintos níveis educacionais e profissionais - por isso tem a oportunidade de desenvolvimento do letramento informacional da comunidade.

De modo geral, percebe-se na literatura um maior empenho no desenvolvimento dos conceitos e terminologias relacionados ao letramento informacional em detrimento de experiências práticas e aplicações empíricas (JULIEN; GENUIS, 2011; GÓMEZ-HERNADEZ; PASADAS-UREÑA, 2007; GASQUE, 2012), principalmente aquelas relacionadas à biblioteca pública.

A notável falta de literatura relacionando os temas letramento informacional e biblioteca pública pode sugerir que as bibliotecas públicas não estão ativamente envolvidas em esforços voltados para o letramento informacional (HARDING, 2008). No entanto, apesar da menor fatia de participação em relação às bibliotecas escolares e universitárias, a literatura internacional mostra que as bibliotecas públicas vêm abraçando este papel e assumindo para si esta responsabilidade.

Deste modo, este artigo tem por objetivo discutir a atuação das bibliotecas públicas em relação ao letramento informacional, além de identificar os principais desdobramentos da temática com base na literatura internacional. Para tanto, o método utilizado foi a pesquisa bibliográfica, que envolveu a identificação e análise das principais pesquisas e discussões presentes na literatura internacional. Apresenta ainda abordagens alternativas de letramento informacional como uma alternativa para a compreensão e o desenvolvimento do letramento informacional no âmbito das bibliotecas públicas. 


\section{Metodologia}

Conforme Alvarenga e Silva (2010), os artigos de revisão representam tentativas de se apresentar o estado corrente da pesquisa, dentro de um recorte particular do campo científico, tendo como intento informar os mais recentes avanços, lacunas expressivas na pesquisa, debates correntes e ideias sobre os rumos em que a pesquisa deve se desenvolver.

No caso do presente artigo, observam-se as seguintes características: quanto ao escopo e método de pesquisa, se reportou a relação entre dois subcampos da ciência da informação, quais sejam o letramento informacional e as bibliotecas públicas; quanto ao método, envolveu a revisão de literatura e a análise de conteúdo, uma vez que identifica e analisa os principais tópicos presentes nas pesquisas relacionadas à temática em questão; não foi realizado um recorte cronológico, no entanto, os artigos analisados correspondem ao período de 1999-2013. Para a seleção dos artigos analisados, foi realizada uma busca no Google Acadêmico utilizando-se os termos information literacy e public libraries, em inglês, e alfabetización informacional e bibliotecas públicas, em espanhol. A partir desta pesquisa, foram selecionados 14 artigos para compor a análise. Foram priorizados na seleção dos artigos as revisões de literatura e os relatos de pesquisas, portanto este não é um trabalho exaustivo.

Considerando que o presente estudo trata-se de uma revisão de literatura internacional e que a literatura analisada sobre as bibliotecas públicas e suas relações com as práticas de letramento informacional foi produzida em contextos diferentes, o objetivo deste trabalho não é incorrer em generalizações, mas sim apresentar as tendências e identificar os temas e abordagens mais recorrentes nas pesquisas sobre o tópico em questão, ou seja, identificar os pontos em comum abordados na literatura.

A partir dos resultados da análise da literatura, se apresentam abordagens alternativas de letramento informacional como uma alternativa para a compreensão e o desenvolvimento do letramento informacional no âmbito das bibliotecas públicas, justamente por considerarem a pluralidade de contextos das bibliotecas públicas. 


\section{Bibliotecas públicas e o letramento informacional: o papel educativo em evolução}

A biblioteca pública desempenha no escopo de suas finalidades diversas funções dentro da comunidade, relacionadas ao seu papel social, cultural, informativo e educativo. É o ponto de acesso principal e dinâmico da comunidade, estruturado para responder de modo proativo a uma multiplicidade de necessidades de informação que estão sempre em mudança (KOONTZ; GUBBIN, 2012).

A função educativa não é um novo papel para a biblioteca pública, que sempre ocupou um lugar na educação desde o início, como um mecanismo para promover hábitos de leitura nas classes trabalhadoras urbanas no século XIX. Foi também nesta época, durante o movimento da biblioteca pública nos Estados Unidos, que surgiu o serviço de referência, quando o acesso às bibliotecas se democratizou devido ao aumento nos níveis de alfabetização da população.

Conforme Campello (2009), o trabalho de referência é definido por alguns autores como uma ação educativa do bibliotecário, que vai além da mera orientação para localizar informações, propiciando a interação entre bibliotecário e usuário. Deste modo concede ao bibliotecário, enquanto mediador, a oportunidade para responder às necessidades informacionais dos usuários, caracterizando-se como um processo de intervenção didática.

No entanto, o fato de o trabalho de referência ser um trabalho realizado por demanda, com o atendimento aos usuários que buscavam ajuda do bibliotecário e a necessidade de encontrar novas maneiras de atender às demandas informacionais de uma clientela que se expandia em busca de educação formal, levou ao aparecimento da educação de usuários, serviço por meio do qual a biblioteca atinge número maior de usuários ao mesmo tempo em que procura satisfazer mais especificamente às suas necessidades de informação. Assim, a educação de usuários ampliou a ação educativa da biblioteca, pois diferentemente do trabalho de referência, tem característica proativa, atendendo aos usuários com cursos, visitas guiadas e outras ações planejadas de ensino do uso da biblioteca e de seus recursos (CAMPELLO, 2009). 
Gómez-Hernandez e Pasadas-Ureña (2007) afirmam que a necessidade de repensar a missão, as metas e os objetivos de seus serviços fez com que o tradicional serviço de formação de usuários nas bibliotecas públicas evoluísse. Antes centrado apenas no uso adequado das instalações e equipamentos da biblioteca e nos recursos de informação impressos, o serviço evoluiu para a realização de programas de letramento informacional, voltados a diferentes grupos, a fim de que adquiram as competências necessárias para buscar e utilizar a informação em todos os suportes, canais e localizações de acordo com suas necessidades. Os autores consideram que esta evolução é uma adaptação às novas circunstâncias e exigências do serviço. No entanto, ponderam que um programa de letramento informacional deve contemplar também as atividades de formação de usuários tradicionais (visitas guiadas, guias de uso de recursos, assistência personalizada), mas de modo que se integrem aos "novos e mais amplos objetivos de aprendizagem", incorporando as atividades de formação da biblioteca ao ambiente educativo formal e informal da comunidade a que serve.

Portanto, o que ocorre não é o surgimento de um novo papel, mas sim uma renovação deste papel diante das novas exigências do atual contexto. $\mathrm{Na}$ Sociedade da Informação o papel educativo da biblioteca pública está voltado para a aprendizagem ao longo da vida, a promoção da educação e do letramento informacional (POUSTIE, 1999).

Para Gasque (2012), as bibliotecas devem ir além do paradigma de acesso à informação para um paradigma pedagógico, ou seja, mais que disponibilizar informação é preciso "[...] envolver a comunidade educativa em programas que possibilitem buscar, decodificar, interpretar e transformar as informações em conhecimento a favor da vida.” (GASQUE, 2012, p. 155).

A responsabilidade e o compromisso das bibliotecas públicas com o letramento informacional e a aprendizagem ao longo da vida se refletem e se figuram em suas diversas declarações de missão e planos estratégicos (GÓMEZHERNANDEZ; PASADAS-UREÑA, 2007; HARDING, 2008). No Manifesto da IFLA/UNESCO sobre bibliotecas públicas (INTERNATIONAL FEDERATION OF LIBRARY...,, 1994), essa questão fica clara ao serem 
apresentadas as seguintes missões da biblioteca pública, que reforçam seu papel educativo e seu compromisso com a aprendizagem permanente:

a) apoiar tanto a educação individual e de iniciativa própria quanto a educação formal em todos os níveis;

b) facilitar o desenvolvimento da capacidade de utilizar a informação e a informática;

c) e apoiar, participar e, se necessário, criar programas e atividades de alfabetização para todos os diferentes grupos etários.

\subsection{Elementos favoráveis ao desenvolvimento do letramento informacional nas bibliotecas públicas}

Apesar da pouca investigação sobre o assunto, é praticamente consenso na literatura que as bibliotecas públicas estão privilegiadamente posicionadas para atuarem como agentes-chaves no desenvolvimento do letramento informacional em suas comunidades. Sua presença constante na vida da comunidade, aliada aos seus objetivos e missões institucionais são os principais fatores que contribuem para isso.

Harding (2008) identificou na literatura sobre o assunto os pontos fortes das bibliotecas públicas no desenvolvimento do letramento informacional, sendo estes:

a) função tradicional e seu reconhecimento como local de aprendizado bibliotecas públicas são reconhecidas desde sua origem como um local de aprendizado;

b) especialistas em letramento informacional - os princípios do letramento informacional estão relacionados aos valores tradicionais das bibliotecas públicas, e bibliotecários são vistos como especialistas em letramento informacional;

c) ampla base de clientes - a diversidade de usuários da biblioteca pública, que deve atender às necessidades de toda a comunidade, desde crianças 


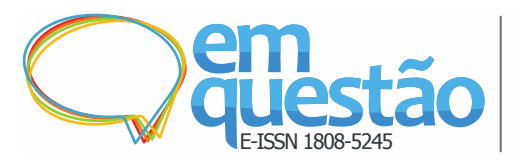

até idosos, grupos minoritários, de níveis educacionais e profissionais diversos, amplia a oportunidade de desenvolvimento do letramento informacional;

d) primeira experiência de aprendizagem da criança - frequentemente a primeira experiência de aprendizado das crianças se dá na biblioteca, seja por experiências como a "hora do conto" ou o primeiro acesso à informação tecnológica. Assim, a biblioteca pode incentivar crianças a valorizar a informação, bem como apoiá-las no aprendizado para o acesso à informação, além de incutir o valor da biblioteca como fonte de informação e local de aprendizagem;

e) contato perene com os membros da comunidade - como o letramento informacional é um processo que se desenvolve ao longo da vida, as bibliotecas públicas estão estrategicamente posicionadas para serem uma presença constante na vida das pessoas, de modo a fornecer suporte contínuo para os indivíduos no desenvolvimento do letramento informacional;

f) os momentos ensináveis - a interação bibliotecário-usuário, como a que ocorre no serviço de referência, é uma forma de desenvolver habilidades de letramento informacional;

g) parcerias - trabalho em conjunto com outras instituições como bibliotecas escolares ou universidades, desenvolvido por bibliotecas públicas;

h) pontos chave de acesso - bibliotecas públicas são fornecedoras de informação impressa e eletrônica, e podem oferecer programas de treinamento e assistência especializada a cidadãos para adquirir habilidades de informação necessárias e desenvolver proficiência no uso dessas fontes. 


\subsection{Dificuldades e desafios}

Problemas estruturais e escassez de recursos são velhos conhecidos das Bibliotecas Públicas em todo o mundo, que lidam diariamente com estes obstáculos para fazer o seu trabalho e desempenhar o seu papel na sociedade. No desenvolvimento do letramento informacional não é diferente. Julien e Hoffman (2008) identificaram os principais desafios enfrentados pelas bibliotecas públicas canadenses na promoção do letramento informacional. Os funcionários destas bibliotecas apontaram os seguintes fatores: desafios sociais mais amplos (como a penetração dos meios de comunicação e questões de inclusão digital), desafios institucionais nas bibliotecas (como marketing, funcionários, orçamento e planejamento de prioridades), problemas de infraestrutura nas bibliotecas e desafios pedagógicos, relacionados ao bibliotecário e seu papel educativo.

Ainda neste sentido, Gómez-Hernandez e Pasadas-Ureña (2007) relacionaram as principais dificuldades apresentadas na inclusão do letramento informacional na agenda das bibliotecas públicas, sendo algumas delas coincidentes com as relacionadas no estudo de Julien e Hoffman (2008). Estas dificuldades estão relacionadas a vários aspectos, quais sejam:

\section{a) relacionadas a aspectos gerais;}

- falta de recursos financeiros, pessoal e equipamentos adequados;

- falta de consciência entre as autoridades de todos os níveis sobre a necessidade de coordenar esforços visando uma gestão mais eficaz dos recursos destinados às atividades de aprendizagem permanente;

- a ausência do letramento informacional nos programas de muitos governos para a realização de qualificações profissionais e o desenvolvimento das competências básicas;

- a falta, até pouco tempo, de programas de letramento informacional planejados especificamente para as necessidades das bibliotecas públicas e poucos exemplos de boas práticas entre os próprios bibliotecários e entre as autoridades e agentes sociais;

b) relacionadas aos profissionais e suas concepções e competências; 


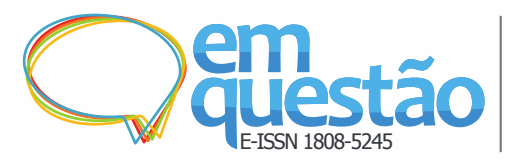

- falta de conhecimento sobre as questões relacionadas ao letramento informacional, tornando necessária a realização de campanhas de conscientização e informação, prévias à realização das atividades de letramento informacional, voltadas para autoridades, agentes sociais e público em geral;

- necessidade de maior colaboração entre os profissionais;

- maior empenho no desenvolvimento dos conceitos e terminologia relacionados ao letramento informacional em detrimento de experiências e aplicações práticas em benefício da população;

- deficiências na formação dos profissionais em competências e habilidades para promover a aprendizagem e o letramento informacional. Pouca reflexão sobre a necessidade de incluir essa pauta nos currículos das universidades ou nas associações profissionais.

c) relacionadas ao usuários;

- dificuldades para realizar atuações específicas para novos grupos de usuários atraídos pela oferta de novos serviços, como a Internet;

- o senso geral de que toda informação está facilmente acessível pela internet sem custos;

d) relacionadas à organização e avaliação;

- poucas alianças entre setores que permeiam a letramento informacional e o aprendizado ao longo da vida, dificuldades de colaboração entre professores do ensino primário e secundário e bibliotecas públicas, ausência de colaboração entre bibliotecários que atuam nos diversos níveis educacionais com as bibliotecas públicas e institucionais;

- dificuldades para a integração dos conteúdos de letramento informacional nos planos de estudo dos diversos níveis da educação formal e ausência de marcos curriculares padronizados para adaptação e ajuste às necessidades locais, sobretudo em bibliotecas públicas e institucionais. Falta de consciência de que a oferta de formação e educação em letramento informacional requer níveis de padronização e 


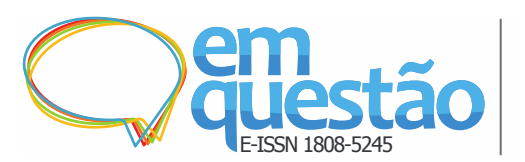

homogeneidade de conteúdos, pois do contrário estaria em risco uma das características fundamentais do letramento informacional, sua possibilidade de transferência;

- poucos instrumentos desenvolvidos para a avaliação e/ou verificação dos avanços pessoais nos programas de letramento informacional, principalmente em contextos de educação não formal, como as bibliotecas públicas;

- falta de formas de avaliação de programas de letramento informacional pelas agências encarregas da qualidade na educação ou no setor público.

Harding (2008) também apontou as principais limitações das bibliotecas públicas aos seus esforços no desenvolvimento do letramento informacional, conforme abaixo:

a) falta de estrutura - apesar da expectativa em relação à biblioteca pública, percebe-se uma falta de linhas de direcionamento de como proceder no desenho e implementação de programas de letramento informacional em bibliotecas públicas e a necessidade de um modelo;

b) recursos - as bibliotecas públicas enfrentam desafios devido às restrições orçamentárias, quadro de pessoal insuficiente, espaço, instalações e infraestrutura inadequados;

c) atitudes e crenças - atitudes e crenças de funcionários e clientes desempenham papel preponderante na efetividade dos programas de treinamento. Bibliotecários tem dificuldade em verem a si mesmos como educadores e usuários tem dificuldades em reconhecer a biblioteca pública como provedora de treinamento em letramento informacional. Além disso, há a necessidade de maior apoio e reconhecimento por parte do governo e da indústria a respeito do papel educativo da biblioteca pública;

d) clientela - a diversidade de clientes da biblioteca pública é uma oportunidade e um desafio, dada à dificuldade de atender e alcançar todos os segmentos da comunidade. Por isso a importância da segmentação e oferta de programas para grupos específicos; 


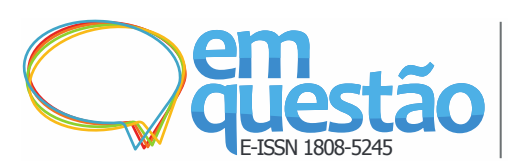

e) a natureza da biblioteca pública - é provável que os esforços de letramento informacional aconteçam mais em função da demanda do que como iniciativa da biblioteca pública;

f) treinamento/habilidades - habilidades pedagógicas não fazem parte da formação do bibliotecário, que deve se aperfeiçoar nesse sentido. Além disso, devem desenvolver suas próprias habilidades e competências informacionais para atuar como agentes de letramento informacional;

g) avaliação - pouca base de como avaliar a efetividade dos programas de letramento informacional e o impacto dos serviços fornecidos tornam difícil elencar justificativas para a continuidade dos serviços;

h) promoção - falta de conhecimento sobre marketing para divulgação dos serviços e alcance dos não usuários;

i) fatores culturais - impactam o trabalho das bibliotecas públicas em várias partes do mundo.

As bibliotecas públicas têm muitos desafios a enfrentar e problemas estruturais, sociais e culturais com que lidar para tornar efetivo o desenvolvimento do letramento informacional. Conforme observa Owusu-Ansah (2003² apud GÓMEZ-HERNANDEZ; PASADAS-UREÑA, 2007), se existem controvérsias não é por falta de uma boa definição (terminológica), mas pela ausência de linhas claras de atuação e de oportunidades para levá-las a cabo - ou seja, não há incertezas conceituais, mas sim dificuldades de aplicação em contextos muito diferentes.

\subsection{O bibliotecário como agente do letramento informacional nas bibliotecas públicas}

A conscientização e o engajamento por parte dos bibliotecários são pontos centrais da questão do letramento informacional nas bibliotecas públicas, uma vez que este profissional deve ter a clareza do seu papel como educador para que possa atuar na formação de competências e habilidades informacionais, considerando o contexto em que atua e as necessidades específicas da sua comunidade. 
Elmborg (2006) discorre sobre as mudanças de demanda nos serviços das bibliotecas associadas à American Research Library (ARL), as quais tiveram uma queda de $26 \%$ no número de atendimentos do serviço de referência e um aumento de 55\% nas apresentações para grupos no período entre 1991 e 2002. Essas mudanças, impulsionadas pela demanda, implicam numa evolução do que fazem os bibliotecários, que passam de provedores de serviços a educadores ativos, o que representa um desafio para os profissionais no sentido de desenvolver novas filosofias de orientação aos usuários. Para o autor, uma forma de fazer frente a esse desafio é que a formação do bibliotecário o prepare mais diretamente para cobrir essas novas funções educativas.

Segundo Lloyd (2005, p. 88, tradução nossa),

Se nós, bibliotecários, queremos ensinar competência informacional e dar base à noção de qualidades transformadoras da competência informacional e sua capacidade de engajar, permitir, enriquecer e incorporar indivíduos em suas práticas, profissões e comunidades, então precisamos ir além do nosso entendimento somente de discurso do que é competência informacional, precisamos entender como as práticas de competência informacional se manifestam nos diversos contextos.

Deste modo, um dos grandes desafios para o profissional da informação e um importante passo para a formação da "cultura informacional" é educar a si próprios e aos outros para a sociedade da informação (TARAPANOFF; SUAIDEN; OLIVEIRA, 2002).

Neste sentido, com o intuito de verificar como os bibliotecários vivenciam o seu papel educativo nas bibliotecas canadenses, Julien e Genuis (2011) realizaram uma pesquisa nacional com 788 funcionários de bibliotecas, onde se explorou a identidade profissional relacionada ao ensino, bem como as experiências e habilidades pedagógicas desses profissionais. Dos questionários respondidos, $25 \%$ foram de profissionais de bibliotecas públicas. Sobre os desafios enfrentados pelos profissionais no desempenho desse papel, Julien e Genuis (2011) identificaram três áreas primárias de dificuldade, quais sejam:

a) desafios externos, contextuais, como ambiente administrativo e tecnologia de ensino; 


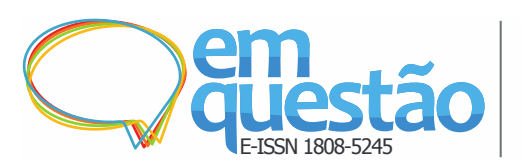

b) desafios da interação com usuários e professores (neste caso, de profissionais de bibliotecas escolares e universitárias); e

c) desafios intrapessoais, relacionados às características pessoais individuais e/ou à falta de preparo para a função educativa.

No estudo de Julien e Genuis (2011), a maioria dos profissionais indicou o papel educativo como parte integrante da identidade profissional, cerca de $1 / 3$ encarou este papel como um dever ou expectativa e uma pequena porção o identificou como uma imposição. Outro dado interessante é que a maioria dos profissionais entrevistados entende que o papel do bibliotecário está em transição e que a função educativa está em expansão. O estudo enfatiza o papel crítico da autoconcepção dos profissionais em relação às suas funções e a importância do apoio dos gestores à capacitação dos profissionais e da valorização do trabalho educativo como formas de influenciar positivamente o modo como os profissionais encaram essa função.

Cientes disso, Demasson, Partridge e Bruce (2010) utilizaram a fenomenografia para verificar como os bibliotecários de bibliotecas públicas de uma região da Austrália concebem, vivenciam e experimentam o letramento informacional. Apesar da pequena amostra, da limitação geográfica e do caráter preliminar do estudo, a investigação é uma importante contribuição e serve de modelo para estudos futuros. O estudo identificou quatro categorias distintas e uma subcategoria, cada uma descrevendo uma forma única com que pelo menos um dos participantes experimentou o fenômeno em questão. As categorias identificadas foram:

a) categoria 1 - social. Os respondentes apontaram o letramento informacional como parte integrante do dia-a-dia da vida das pessoas. Nesta categoria, o foco principal é o desenvolvimento de habilidades que permitirão ao indivíduo viver com sucesso em um mundo dominado pela informação; 


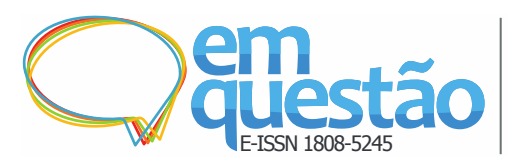

b) categoria 2 - intelectual/avaliativo. O letramento informacional se constitui como um processo intelectual, onde as pessoas não apenas têm a consciência de todas as possíveis maneiras de acessar as informações, como são capazes de avaliar sua validade, confiabilidade e valor. Nesta categoria, o foco principal é fazer uma escolha informada e fundamentada quanto à fonte de informação, ferramenta ou recurso mais confiável, válido e apropriado dentre os muitos que estão disponíveis;

c) categoria 3 - técnica/tecnológica/prática. Constitui o letramento informacional como a capacidade de usar as ferramentas de tecnologia da informação para acessar informações;

d) categoria 3A - resultado e não processo: constitui o letramento informacional como forma para alcançar um objetivo predeterminado. $\mathrm{O}$ foco principal é a obtenção de um resultado desejado por meio do uso da informação. É visto como um resultado e não um processo;

e) categoria 4 - falta de significado. O letramento informacional é constituído como um processo, conceito ou teoria que não tem um significado específico. Nesta categoria, o foco primário é a falta de identificação e envolvimento com o conceito de letramento informacional.

\subsection{Cooperação e parcerias}

Outro ponto com bastante destaque é a importância da cooperação entre bibliotecas públicas e outras instituições para o desenvolvimento do letramento informacional. O trabalho colaborativo com bibliotecas escolares, universidades, lideranças comunitárias, entre outros, enriquece e diversifica a experiência da biblioteca pública com o letramento informacional (ELMBORG, 2006; HALL, 2010; HARDING, 2008; LAI, 2011; ).

Harding (2008) destaca o trabalho desenvolvido com parcerias como um importante ponto de atuação da biblioteca pública na promoção do letramento informacional, que se dão de formas variadas. A forma de parceria mais 
defendida é a estabelecida entre bibliotecas públicas e escolas ou instituições acadêmicas, ou, ainda, as parcerias entre bibliotecas públicas e provedores de informação comunitária, entidades governamentais e empresas privadas e entre bibliotecas públicas e indivíduos da comunidade, como voluntários.

Os manifestos da IFLA/UNESCO destacam a importância da cooperação educativa entre bibliotecas públicas e escolares. Nas Diretrizes IFLA/UNESCO para o desenvolvimento dos serviços da biblioteca pública (KOONTZ; GUBBIN, 2012), essa relação é definida como uma das relações institucionais mais importantes. Entre as formas de cooperação elencadas, destaca-se a cooperação no desenvolvimento de ferramentas de aprendizagem e a programação de esclarecimentos sobre a internet para crianças. As Diretrizes IFLA/UNESCO para a biblioteca escolar também reforçam o trabalho conjunto entre bibliotecas escolares e públicas (INTERNATIONAL FEDERATION OF LIBRARY...,, 2002).

A Declaração de Maceió sobre competência em informação também aborda esta questão. O documento ressalta a necessidade de bibliotecas, instituições e profissionais interessados no fomento e na promoção da competência em informação, estabelecerem relações para a coordenação e desenvolvimento de ações conjuntas (FEDERAÇÃO BRASILEIRA DE BIBLIOTECÁRIOS, CIENTISTAS DA INFORMAÇÃO E INSTITUIÇÕES, 2011).

Para Lai (2011), as bibliotecas públicas podem expandir seus serviços mantendo relações com outras instituições locais, como centros comunitários, centros de idosos, escolas e universidades, de modo a enriquecer as experiências de aprendizagem da comunidade. A autora cita o exemplo do trabalho colaborativo realizado entre bibliotecas públicas e serviços de imigrantes, oferecendo cursos aos imigrantes, contribuindo para sua integração com canadenses nativos, além de auxiliar na procura por emprego.

O estabelecimento de parcerias e a realização de trabalho cooperativo e colaborativo reflete a capacidade da biblioteca pública de se engajar e dialogar com outros setores da comunidade visando o cumprimento de seu papel social e educativo. Neste sentido, torna-se vital uma postura ativa, aberta e acolhedora 
rumo ao novo papel que se desdobra do fruto das relações e do trabalho conjunto com outras instituições e com a própria comunidade.

\subsection{Além do acesso às tecnologias}

O Manifesto da IFLA/UNESCO sobre a Internet (2006) estabelece que as bibliotecas têm a responsabilidade de facilitar e promover o acesso público à informação de qualidade e à sua comunicação. Também estabelece que "[...] devem ser oferecidos aos usuários a orientação necessária e o ambiente adequado para que eles possam usar, com liberdade e confiança, as fontes e os serviços de informação de sua escolha." (INTERNATIONAL FEDERATION OF LIBRARY...,, 2006, doc. não paginado) e por fim enfatiza o papel educativo dos bibliotecários, responsáveis por “[...] prover as informações e os recursos para que os usuários aprendam a utilizar a Internet e a informação eletrônica eficazmente.” (INTERNATIONAL FEDERATION OF LIBRARY...,, 2006, grifo nosso, doc. não paginado).

Atualmente, na maioria dos casos, a informação pode ser facilmente recuperada através da internet, no entanto é comum que pessoas gastem um valioso tempo por falta de competências adequadas para identificar os recursos mais apropriados e para encontrar, avaliar e utilizar a informação de forma eficaz na resolução de problemas (BADKE, $2008^{3}$ apud LAI, 2011).

Em adição ao fornecimento de acesso gratuito à internet, serviço comumente ofertado por bibliotecas públicas ao redor do mundo, muitas bibliotecas têm implementado programas de treinamento para utilização das Tecnologias de Informação e Comunicação (TICs). Para Harding (2008), parece ser nessa área que as bibliotecas públicas mais fizeram incursões relacionadas ao letramento informacional, pois de nada adianta ofertar recursos tecnológicos se os indivíduos não possuem as habilidades necessárias para acessá-los ou usá-los eficazmente. Harding (2008) cita iniciativas de bibliotecas públicas que desenvolveram programas voltados para grupos específicos, como treinamento em TICs para idosos e grupos minoritários, na Noruega, treinamento para o uso de recursos eletrônicos da biblioteca, como bases de dados e sites específicos, 
no Canadá. e a oferta de cursos de habilidades computacionais básicas, na Austrália. Outras bibliotecas vão além e expandem o treinamento para a avaliação dos recursos, geralmente em conjunto com o treinamento em internet: uso inteligente de internet, na Espanha, usando a internet eficazmente, na Austrália, e avaliação crítica do conteúdo online, nos Estados Unidos.

A partir disso, destaca-se o papel das bibliotecas públicas não apenas na disponibilização de acesso às TICs, mas também no desenvolvimento de competências e habilidades que possibilitem aos usuários ter acesso a esses recursos e utilizá-los para buscar, localizar e usar a informação. Deste modo, o papel das bibliotecas públicas presta importante contribuição para a inclusão digital, à medida que além de fornecer o acesso, desenvolve competências para o seu uso efetivo, em prol da cidadania e melhoria da qualidade de vida.

\section{Letramento informacional: abordagens alternativas}

A expressão information literacy foi usada pela primeira vez em 1974, pelo bibliotecário americano Paul Zurkowski, em um relatório intitulado The information service environment relationships and priorities. Zurkowski previa um contexto de mudanças para os anos seguintes e alertava a necessidade do aprendizado de técnicas e habilidades no uso de ferramentas de acesso à informação. Em seu relatório, recomendava o início de um “[...] movimento nacional em direção à information literacy.” (DUDZIAK, 2003, p.24).

Os termos utilizados para traduzir a expressão são muitos, como alfabetización informacional (ALFIN), utilizado na Espanha e em alguns países latinos, e literacia da informação, utilizado em Portugal. No Brasil, já foram utilizados os termos information literacy, alfabetização informacional, habilidade informacional, competência informacional e letramento informacional.

Gasque (2011) afirma que embora esses conceitos estejam relacionados entre si, não devem ser empregados como sinônimos, uma vez que representam ações, eventos e ideias diferentes. Neste sentido, propõe-se um arcabouço conceitual para o letramento informacional, ainda que em "natureza incipiente de esboço", como definido pela própria autora, baseado na literatura da área 
educacional. Conforme este arcabouço, a autora apresenta os seguintes conceitos:

a) alfabetização informacional - primeira etapa do processo de letramento. Envolve o conhecimento básico dos suportes de informação, compreensão de conceitos relacionados à busca e ao uso da informação, domínio das funções básicas do computador;

b) competência informacional - expressão do "saber fazer". Derivada das relações entre o conhecimento que o sujeito detém, experiência adquirida e reflexão sobre a ação;

c) habilidades informacionais - realização de cada ação específica e necessária para alcançar determinada competência;

d) letramento informacional - o engajamento do sujeito nesse processo de aprendizagem a fim de desenvolver competências e habilidades necessárias à busca e ao uso de informação de modo eficiente e eficaz. Processo de aprendizagem contínuo e prolongado ao longo da vida.

Deste modo, para os fins deste estudo, foi adotada como tradução para information literacy o termo letramento informacional, expressão de um processo de aprendizagem contínuo ao longo da vida.

A American Library Association (ALA) (1989) define letramento informacional como a capacidade de reconhecer quando uma informação é necessária, onde localiza-la, como avalia-la e como utiliza-la de modo eficaz, e em última análise, representa a capacidade de aprender a aprender. Para além desta definição, o conceito tem sido reformulado e ampliado considerando o contexto e as relações sociais envolvidas.

A definição tradicional - entendida como um conjunto de habilidades cognitivas para o uso da informação - vem sendo questionada por alguns autores, que apontam suas deficiências e propõem a expansão do conceito e a adoção de abordagens alternativas para o letramento informacional. É o caso de pesquisadores como Elmborg (2006) e Hall (2009), que utilizam elementos e autores da pedagogia crítica como Paulo Freire e John Dewey para propor uma 
critical information literacy ou letramento informacional crítico (tradução nossa), e Lloyd (2005; 2010), que defende information literacy landscapes, contextos de letramento informacional ou paisagens de letramento informacional (tradução nossa), e sugere uma visão contextualizada do letramento informacional utilizando uma perspectiva sociocultural.

Elmborg (2006) critica as definições de letramento informacional adotadas pela Association of College \& Research Libraries (ACRL) e pela bibliografia de biblioteconomia por omitirem questões centrais que afetam estudantes, docentes, comunidades e bibliotecas, e cita Norgaard $(2003)^{4}$ ao fazer um apelo para que as bibliotecas participem do movimento do letramento informacional, distanciando-se das definições instrumentais baseadas em habilidades e buscando uma compreensão do letramento informacional como um fenômeno "culturalmente situado" baseado no modo como as comunidades constroem significado e ideia de pertencimento.

Como alternativa ao conceito tradicional o autor propõe uma reflexão baseada nas teorias críticas da pedagogia, e a inclusão do elemento crítico ao conceito de letramento informacional. Para Elmborg (2006), as bibliotecas e os bibliotecários devem centrar-se menos na transferência do conhecimento e preocupar-se mais com a formação da consciência crítica das pessoas, a partir da qual é possível formar agentes ativos, capazes de formular e responder questões que os afetam diretamente ou ao mundo à sua volta.

Ou seja, a questão também permeia reflexões profundas sobre o papel educativo da biblioteca e do bibliotecário, que devem pensar criticamente e questionar sua formação e suas práticas. Conforme Elmborg (2006), a partir dessa mudança de postura os bibliotecários deixam de estudar a biblioteca como matéria e se convertem em especialistas em treinamento e crescimento intelectual e crítico. No entanto, só podem ajudar a realizar a "viagem" ou a percorrer o "caminho" do crescimento intelectual se eles mesmos forem capazes de fazê-lo, daí a importância de repensar a formação do bibliotecário.

Hall (2010) se apoia nas ideias expostas por Elmborg (2006) e nas teorias educacionais de John Dewey e Paulo Freire, e também propõe uma critical information literacy, convocando os bibliotecários a irem além do 
ensino de habilidades informacionais e tecnológicas e encorajando o desenvolvimento de um letramento informacional em ação, baseado no que Paulo Freire chamou de "práxis".

Para Hall (2010), os bibliotecários não devem pensar o letramento informacional como um processo neutro ou fora de contexto, nem nos usuários simplesmente como "depósitos" de competências informacionais e que respondem da mesma forma ao mesmo estímulo. Devem, por outro lado, depois de terem introduzido em suas comunidades novos modos de armazenamento, recuperação e criação de informação, levantar problemas e agir sobre o mundo a fim de mudá-lo. Deste modo, devem buscar se engajar com a sua comunidade para resolver problemas e buscar soluções, utilizando o letramento informacional de forma crítica e contextualizada voltada para a práxis, ou seja, para a ação.

Buscando uma redefinição do conceito, Lloyd (2005; 2010) sugere uma desconstrução do discurso, de modo a construir uma visão holística, um conceito mais amplo para além da estrutura formal, levando em conta o contexto de modo a ampliar o conhecimento das múltiplas realidades da vida cotidiana, que são aumentadas pelo acesso efetivo, mas diverso à informação. Ou seja, amplia o intento do letramento informacional e o traz para outros contextos, como o ambiente de trabalho e a vida comunitária, onde o acesso à "informação social" permite um "aprendizado personificado". Configura-se, portanto, em atividade colaborativa e social, dependente de relacionamentos pessoais e comunitários.

Lloyd (2005) sugere que pode ser problemático para a causa apresentar uma única concepção de verdade. Por isso afirma que é imprescindível desenvolver maneiras de explorar o letramento informacional que permitam o desenvolvimento de um conceito mais amplo que atinja os interesses da educação, local de trabalho e comunidade. Deste modo será possível construir um quadro genérico de habilidades (relacionando aprendizado textual, social e corpóreo) e competências que possam ser ensinadas em diversos cenários, de modo a facilitar o desenvolvimento de habilidades e competências que permitam e enriqueçam o aprendizado ao longo da vida. 
A possibilidade de ouvir outras vozes além da educacional, a respeito do letramento informacional expande as possibilidades de sua conceituação e de qual é e qual deve ser o seu papel. Permite dessa forma entender o letramento informacional como uma "meta-competência", ou seja, uma série de competências que permitem novas habilidades e conhecimentos em uma variedade de contextos (KEARNS, $2001^{5}$ apud LLOYD, 2005).

Os preceitos defendidos por Elmborg (2006), Hall (2010) e Lloyd (2005;2010) guardam semelhanças entre si por proporem abordagens alternativas para a compreensão do fenômeno. Os três autores buscam uma redefinição do conceito de letramento informacional, compreendido de uma perspectiva holística como uma prática cultural e socialmente contextualizada e apresentam uma alternativa bastante útil para embasar as práticas de letramento informacional nas bibliotecas públicas.

\section{Breves conclusões}

A partir da revisão da literatura da área foi possível situar o letramento informacional no contexto das bibliotecas públicas. Observou-se que o letramento informacional tem se mostrado um conceito dinâmico, que surgiu com um determinado propósito e que vem se ampliando conforme avançam as pesquisas e a sociedade. O conceito inicial relacionado a habilidades cognitivas para o acesso e uso efetivo da informação amplia-se a partir do entendimento do letramento informacional como um fenômeno social e culturalmente situado, essencial para a plena participação na Sociedade da Informação, para o exercício da cidadania e participação na democracia, para o engajamento no processo de aprendizagem, o aprendizado autônomo ao longo da vida e para o empoderamento social individual e coletivo.

Abordagens alternativas, como a relacional utilizada por Bruce (2003), a abordagem crítica defendida por Elmborg (2006) e Hall (2010) e a abordagem social proposta por Lloyd (2005) mostram que há várias formas de conceituar e vivenciar o letramento informacional e que não há uma única verdade, mas sim múltiplos contextos. Esta compreensão é bastante útil para lidar com o 
fenômeno, principalmente no âmbito da biblioteca pública, que transita por tantas vertentes da comunidade e está situada em realidades tão múltiplas. Os elementos presentes nestas abordagens alternativas, como o pensamento crítico e a interação social e cultural são fundamentais para pensar o letramento informacional no contexto das bibliotecas públicas, considerando que mais do que transformar a biblioteca em sala de aula, é preciso engajar-se com a comunidade e promover uma ação transformadora.

As pesquisas e estudos que abordam o letramento informacional e as bibliotecas públicas mostraram-se bastante reduzidos. A maior parcela dos estudos utilizados neste trabalho foi de língua inglesa, oriundos principalmente dos Estados Unidos, Canadá, Austrália e Inglaterra, além de alguns estudos em língua espanhola. Nos estudos realizados no Brasil foram encontradas apenas algumas menções sobre as bibliotecas públicas, mas nenhum trabalho específico sobre a questão.

Observou-se também que a função educativa não é um papel novo para as bibliotecas públicas, pelo contrário - sempre esteve presente em sua linha de atuação. O que há é uma reconfiguração de antigos papeis para atender às novas demandas e necessidades geradas pela sociedade, além do posicionamento privilegiado e estratégico da biblioteca pública na comunidade, configurando-a como ambiente ideal para o aprendizado permanente.

Além dos aspectos que privilegiam a biblioteca pública, a pesquisa apontou para oportunidades de atuação, relacionadas à inclusão digital e ao trabalho colaborativo com outras instituições, por exemplo. A alta penetração das tecnologias da informação e o seu uso massivo para o acesso à informação a tornam um ponto importante a ser considerado quando se trata de letramento informacional. E as bibliotecas públicas, neste sentido, mais do que prover acesso a essas tecnologias, devem fornecer meios para capacitar a comunidade para seu uso crítico e eficaz, contribuindo para a inclusão digital e a democratização do acesso à informação.

No que tange à cooperação com outras instituições, é possível perceber que se trata de um ponto crucial para a atuação das bibliotecas públicas na promoção do letramento informacional. A cooperação mais citada e 
recomendada envolve bibliotecas escolares e instituições educacionais, dentre outras instituições e até membros da comunidade. Além disso, foram identificadas nos diversos estudos e investigações, diversas barreiras e dificuldades enfrentadas pela biblioteca pública nesta empreitada do letramento informacional. A falta de recursos e infraestrutura necessária é uma das principais questões, além de aspectos culturais e sociais, e as próprias atitudes e crenças: de um lado estão os bibliotecários, que muitas vezes não se veem como educadores, e de outro os usuários, que tem dificuldade em reconhecer a legitimidade da biblioteca pública enquanto espaço educativo.

Quanto aos bibliotecários, apesar de serem apontados como “especialistas em letramento informacional”, muitos ainda não estão totalmente familiarizados com a questão - o que leva a uma séria reflexão, tendo em vista a influência exercida pela sua autoimagem em sua atuação.

Desta forma, cabe enfatizar a necessidade de trabalhos empíricos envolvendo as bibliotecas públicas, os bibliotecários que nelas atuam e suas práticas de letramento informacional - principalmente no Brasil, onde o assunto é pouco abordado na literatura.

\section{Referências}

ALVARENGA, Lídia; SILVA, Daniela Lucas. Organização e representação do conhecimento na ciência da informação: revisão da literatura. Pesquisa Brasileira em Ciência da Informação, Brasília, v. 3, n. 1, p. 47-84, jan./dez. 2010.

AMERICAN LIBRARY ASSOCIATION. Presidential Committee on Information Literacy: final report. 1989. Disponível em: <http://www.ala.org/acrl/publications/whitepapers/presidential> Acesso em: 15 ago. 2014.

BRUCE, Christine Susan. Las siete caras de la alfabetización en información en la enseñanza superior. Anales de Documentación, Múrcia, n. 6, p. 289-294, 2003.

BRUCE, Harry; LAMPSON, Marc. Information professionals as agentes of information literacy. Education for Information Journal, New York, n. 20, p. 
81-106, 2002.

CAMPELLO, Bernadete. Letramento informacional no Brasil: práticas educativas de bibliotecários em escolas de ensino básico. 2009. Tese.

(Doutorado em Ciência da Informação) Universidade Federal de Minas Gerais, Belo Horizonte, 2009.

DEMASSON, Andrew; PARTRIDGE, Helen; BRUCE, Cristine. How do public librarians constitute information literacy? In: CONFERENCE ON

QUANTITATIVE RESEARCH IN IT, 5., 2010, Brisbane. Brisbane, 2010.

DUDZIAK, Elizabeth Adriana. Information Literacy: princípios, filosofia e prática. Ciência da Informação, Brasília, v. 32, n. 1, p. 23-25, 2003.

ELMBORG, James. Critical information literacy: implications for instructional practice. The Journal of Academic Librarianship, Texas, v. 32, n. 2, p. 192199, 2006. Disponível em: < http://eric.ed.gov/?id=EJ737617>. Acesso em: 15 jan. 2014.

FEDERAÇÃO BRASILEIRA DE BIBLIOTECÁRIOS, CIENTISTAS DA INFORMAÇÃO E INSTITUIÇÕES. Declaração de Maceió sobre a competência em

informação. In: Congresso Brasileiro de Biblioteconomia e Documentação, 24., 2011. Maceió, 2011. Disponível em:

<http://febab.org.br/declaracao_maceio.pdf>. Acesso em 15 jan. 2014.

GASQUE, Kelley Cristine Gonçalves Dias. Letramento informacional: pesquisa, reflexão e aprendizagem. Brasília: FCI/UnB, 2012.

GASQUE, Kelley Cristine Gonçalves Dias. Arcabouço conceitual do letramento informacional. Ciência da Informação, Brasília, v. 39, p. 83-92, 2011.

GÓMEZ-HERNANDEZ, J. A.; PASADAS-UREÑA, Cristóbal. La

alfabetización informacional en bibliotecas públicas: situación actual y propuestas para una agenda de desarrollo. Information Research, [S.1.], v. 12, n. 3, p. 1-25, 2007. Disponível em: <

http://eprints.rclis.org/9418/1/alfabetizacion.pdf>. Acesso em: 15 jan. 2014.

HALL, Rachel. Public Praxis: A vision for critical information literacy in public libraries. Public Library Quartely, Chicago, v. 29, n. 2, p. 162-175, 2010.

Disponível em:

<http://www.tandfonline.com/doi/abs/10.1080/01616841003776383>. Acesso em: 15 jan. 2014.

HARDING, Jane. Information literacy and the public library: we've talked the talk, but are we walking the walk? The Australian Library Journal, Deakin, v. 57, n. 3, p. 274-294, 2008. Disponível em: 〈http://eric.ed.gov/?id=EJ813746>. Acesso em: 15 jan. 2014. 
INTERNATIONAL FEDERATION OF LIBRARY ASSOCIATIONS AND INSTITUTIONS. Declaração de Alexandria sobre competência informacional e aprendizado ao longo da vida. In: NATIONAL FORUM ON INFORMATION LITERACY, 2005. Disponível em: <

http://archive.ifla.org/III/wsis/BeaconInfSoc-pt.html>. Acesso em: 15 jan. 2014.

INTERNATIONAL FEDERATION OF LIBRARY ASSOCIATIONS AND INSTITUTIONS. Diretrizes da IFLA/UNESCO para a biblioteca escolar. Holanda: IFLA, 2002. Disponível em: < http://www.ifla.org/files/assets/schoollibraries-resource-centers/publications/school-library-guidelines/school-libraryguidelines-pt_br.pdf>. Acesso em: 15 jan. 2014.

INTERNATIONAL FEDERATION OF LIBRARY ASSOCIATIONS AND INSTITUTIONS. Manifesto IFLA/UNESCO sobre a internet. Holanda: IFLA, 2006. Disponível em: <http://www.ifla.org/III/misc/internetmanif.htm> Acesso em: 15 jan. 2014.

INTERNATIONAL FEDERATION OF LIBRARY ASSOCIATIONS AND INSTITUTIONS. Manifesto IFLA/UNESCO sobre a biblioteca pública. Holanda: IFLA, 1994. Disponível em:

<http://archive.ifla.org/VII/s8/unesco/port.htm>. Acesso em: 15 jan. 2014.

JULIEN, Hedi; GENUIS, Shelagh K. Librarian's experiences of the teaching role: a national survey of librarians. Library \& Information Science Research, Boston, v. 33, p. 103-111, 2011. Disponível em:

<http://ejournals.library.ualberta.ca/index.php/EBLIP/article/downloadSuppFile/ 10979/1882>. Acesso em: 15 jan. 214.

JULIEN, Hedi; HOFFMAN, Cameron. Canada's public libraries and information literacy training. Canadian Library Association, Ottawa, n. 2, p. 74-77, 2008.

KOONTZ, Christie; GUBBIN, Barbara (Org.). Diretrizes da IFLA para bibliotecas públicas. Brasília: Briquet de Lemos, 2012.

LAI, Horng-Ji. Information literacy training in public libraries: a case from Canada. Educational Technology \& Society, Palmerston North, v. 14, n. 2, p. 81-88, 2011.

LLOYD, Annemaree. Information literacy: Different contexts, different concepts, different truths? Journal of librarianship and information science, [S.l], v. 37, n. 2, p. 82-88, 2005. Disponível em:

<http://lis.sagepub.com/content/37/2/82.abstract>. Acesso em: 15 jan. 2014.

LLOYD, Annemaree. Information literacy landscapes. London: Chandos, 2010. 
POUSTIE, Kay. Educating for information literacy through the internet: another role of the public library. Australian Public Libraries and Information Services, Austrália, v. 12, n. 2, jun. 1999.

TARAPANOFF, Kira; SUAIDEN, Emir; OLIVEIRA, Cecília Leite. Funções sociais e oportunidades para profissionais da informação. DataGramaZero: revista de Ciência da Informação, Rio de Janeiro, v. 3, n. ,5 out. 2002.

\title{
Information literacy and public libraries
}

\begin{abstract}
Identified by several authors as an essential institution for the development of a citizen, the Information Society presents new challenges and opportunities for public libraries and its duty to develop a citizen able to survive in the Information Society. In this sense, information literacy stands out since it's essential for the development of autonomous learners, able to access information and use it in a critical and ethical way. Therefore, this article discusses the roles of public libraries in promoting information literacy. To accomplish its goals, this paper's methodology was bibliographical research, identifying and analyzing the main subjects of research and discussions in the literature nowadays. It also shows alternative approaches to information literacy as an alternative way to the understanding and the development of information literacy within the Public Libraries. The result of these analyses identified the main issues that permeate the subject of this investigation.
\end{abstract}

Keywords: Informational Literacy. Public Libraries.

Recebido: 08/04/2015

Aceito: 13/08/2015 
1 KAHLERT, M. Lifelong learning: a public library perspective. In: ALIA 2000: capitalizing on knowledge: the information profession in the 21st century. Canberra, 2000. Disponível em: <http://conferences.alia.org.au/alia2000/proceedings/maureen.kahlert.html〉. Acesso em: 5 mar. 2007.

2 OWUSU-ANSAH, E. K. Information literacy and the academic library: a critical look at a concept and the controversies surrounding it. The Journal of Academic Librarianship, [S.1.], v. 29 n. 4, p. 219-230, 2003.

${ }^{3}$ BADKE, W. Ten reasons to teach information literacy for credit. Online, [S.1.], v. 32 n. 6, p. 47-49, 2008.

${ }^{4}$ NORGAARD, Rolf. Writing Information Literacy: Contributions to a Concept. Reference and user services quarterly, [S.1.], v. 43 n. 2, 2003, p. 124-130.

${ }^{5}$ KEARNS, P. Generic Skills for the New Economy: a review of research. Leabrook: NCVER, 2001. 